\title{
Volumetry of Hydrogen Micro-bubbles Dispersed in
}

\section{Water}

\author{
Koichi Jeremiah Aoki ${ }^{1}$, Shinpei Yamaguchi ${ }^{2}$ and Jingyuan Chen ${ }^{1}$ \\ 1. Electrochemistry Museum, Tagagichuo, Fukui 910-0804, Japan \\ 2. Graduate School of Engineering, University of Fukui, Fukui 910-0015, Japan
}

\begin{abstract}
When hydrogen gas is bubbled in water until saturation, micro-bubbles with ca. $0.5 \mu \mathrm{m}$ in diameter have been detected in water by the dynamic light scattering, reportedly. A part of saturated hydrogen may take gas form, whereas it may take hydrated form. A question is how much molar ratio of the two forms. If hydrogen molecule is oxidized to hydronium ion, the volume of the solution including bubbles should decrease by the amount of gas form more predominantly than that of the hydronium one. Herein we oxidized the saturated hydrogen gas with potassium permanganate in the presence of platinum wire as catalyst. The decrease in the volume of the gas was compensated for addition of water so that the pressure of the hydrogen gas was able to be kept to the atmospheric pressure. From the decrease in the volume under the steady state, concentrations of $\mathrm{H}_{2}$ in the gaseous form were evaluated at several temperatures to be ca. $0.4 \mathrm{mM}$, which is a half the saturated concentration of $\mathrm{H}_{2}$. They were almost independent of the temperature of bubbling.
\end{abstract}

Key words: Hydrogen micro-bubbles, stability of dispersed gas in water, measurements of gas volume, supersaturation of hydrogen gas.

\section{Introduction}

A gas chemically inactive to a liquid dissolves in the liquid, of which concentration is proportional to the partial pressure of the gas, according to Henry's law [1]. The proportional coefficient is called the Henry's coefficient or specifically the Bunsen solubility coefficients at $0{ }^{\circ} \mathrm{C}$ under 1 atm $(101.3 \mathrm{kPa})$ [2-4]. The coefficients have been practically determined from saturated concentrations and partial pressures. For example, reported values of saturated hydrogen gas at $1 \mathrm{~atm}$ at $25^{\circ} \mathrm{C}$ are $0.78 \mathrm{mM}(\mathrm{M}=\mathrm{mol}$ $\mathrm{dm}^{-3}$ ) in water [5, 6], 0.56 $\mathrm{mM}$ in $1.1 \mathrm{M}$ aqueous $\mathrm{NaCl}$ solution, and $0.63 \mathrm{mM}$ in $0.2 \mathrm{M}$ aqueous $\mathrm{BaCl}_{2}$ solution [7-9]. Since the saturated concentrations decrease with the time without a supply of gas in water [10], they should belong to dynamic properties. Therefore the experimentally evaluated Henry's coefficients do not obey the thermodynamic concept

Corresponding author: Jingyuan Chen, Ph.D., professor, research fields: electrochemistry, physical chemistry. of Henry's law. The time-dependent coefficients are caused by buoyancy-driven rising bubbles, accompanied with aggregation of bubbles. The convection has often been observed during evolution of electrochemically generated gasses [11-19].

It is obvious that a smaller bubble has slower rising speed and hence a longer life-time. When a spherical bubble with a radius $r$ rises in water by buoyancy at the steady speed $v$, the buoyancy is balanced with the frictional force against the rising bubble. Then we have $(4 \pi / 3) r^{3} \rho g=6 \pi \eta r v$, where $\rho$ is the density of water, $g$ is the gravity, and $\eta$ is the viscosity of water. The extraction of $v$ yields $v=(2 / 9) r^{2} \rho g / \eta$ [20], of which numerical values for $2 r=20,2.0,0.4$ and 0.2 $\mu \mathrm{m}$ are $0.24 \mathrm{~mm} \cdot \mathrm{s}^{-1}, 2.4 \mu \mathrm{m} \cdot \mathrm{s}^{-1}, 0.10 \mu \mathrm{m} \cdot \mathrm{s}^{-1}$ and 0.024 $\mu \mathrm{m} \cdot \mathrm{s}^{-1}$, respectively, at $\eta=0.89 \mathrm{mPa} \cdot \mathrm{s}$. These speeds correspond to $40 \mathrm{~s}, 1 \mathrm{~h}, 1$ day and 5 days for $1 \mathrm{~cm}$ rise. Since diameters of electrolyzed evolving gases range from 20 to $200 \mu \mathrm{m}$ [17-23], the bubbles float soon to disappear in solution. Consequently the Henry's coefficients for electrochemically generated bubbles 
should decrease with the time of measurements. Determination of gas solubility at short time has been made by use of variations of volume or pressure reaching the saturated state [24-28]. Convenient and rapid measurements of solubility of hydrogen gas are potentiometry and amperometry of the electrochemical oxidation of hydrogen [9, 29, 30]. They have been applied conveniently to piezoelectric pressure sensors [31], pressure transducers [32] and differential pressure indicators [33], although they are not supported by thermodynamics.

When water phase comes in quiescent contact with oil phase, each phase near the boundary has contained droplets of the other phase [34, 35]. Self-emulsification has been found even in bulk phase [36-39]. The emulsification has been demonstrated theoretically by statistical mechanics of various droplets on the assumption that the oil/water surface tension was balanced with entropy of droplets [40]. This theory can be extended to gas/liquid surface without a loss of generality. Then it is predicted that hydrogen gas not only dissolves in water to hydrated molecules but also is dispersed in bubble form on a micrometer scale under quasi-equilibrium. It is the hydrated hydrogen that can take part in chemical reactions as a reducing agent in water rather than gas bubbles. Therefore it is important to estimate the concentration of the hydrated form for practical use of fuel cells.

It is not easy to discriminate chemically the hydrated form from the bubble form. It is the relation of volume with pressure that makes clear difference between gas and liquid phases. We estimated the gas volume of $\mathrm{H}_{2}$ from the algebraic product of the number of bubbles by the volume of micro-bubbles, which were determined by light scattering [10]. However, this method is based on uniform size of bubbles, and hence does not provide the accurate volume of the gas. It is necessary to evaluate the total gas volume directly. If $1 \mathrm{mmol} \mathrm{H}_{2}$ gas is dispersed into $1.000 \mathrm{dm}^{3}$ water in the bubble form, the total volume is ca. $1.024 \mathrm{dm}^{3}$ at $25{ }^{\circ} \mathrm{C}$ under $1 \mathrm{~atm}$. In contrast, the hydrated hydrogen does not vary the volume as much as $0.024 \mathrm{dm}^{3}$ because of the hydration. The difference in volume can be applied to determine the content of the gas. We here develop the volumetry of saturated hydrogen gas in water. The technique is to evaluate the difference in volumes of water with and without hydrogen gas. Our process is to prepare a tightly sealed given volume of $\mathrm{H}_{2}$-saturated water under $1 \mathrm{~atm}$, to oxidize hydrogen chemically to hydronium ion keeping the pressure, and to measure the volume. The decrease in the volume should correspond to the amount of gas bubbles of hydrogen. Although the concept is simple, the experiment includes some complications to be overcome.

\section{Materials and Methods}

The volumetric apparatus for the hydrogen gas is illustrated in Fig. 1A. It consisted of $1 \mathrm{dm}^{-3}$ in a three-necked round flask with ground glass joints, a burette-type manometer with a volume change of 50 $\mathrm{cm}^{3}$, a water tank, a magnetic stirrer, and an injector $200 \mathrm{~cm}^{3}$ in volume. The injector was driven by a worm drive so that it injected water into the flask and withdrew it from the flask, respectively, for $P_{\text {in }}<P_{\text {out }}$ and $P_{\text {in }}>P_{\text {out }}$, where $P_{\text {in }}$ and $P_{\text {out }}$ are the pressures in the flask and the atmosphere. The injector worm drive was turned round with a stepping motor, controlled with the stepping motor driver A4988 (Allegro), as illustrated in Fig. 1B. A stepping net volume was ca. 5 $\mathrm{mm}^{3}$, including backlash.

The equi-pressure control was required to minimize leakage of gas from joints during a long time measurement when there was difference between the inner pressure and the atmospheric pressure. All the glass joints were sealed with vacuum grease. Temperature of air in the flask was controlled by immersing the flask into thermo-controlled bath up to the neck of the flask. The volumeter was calibrated by 


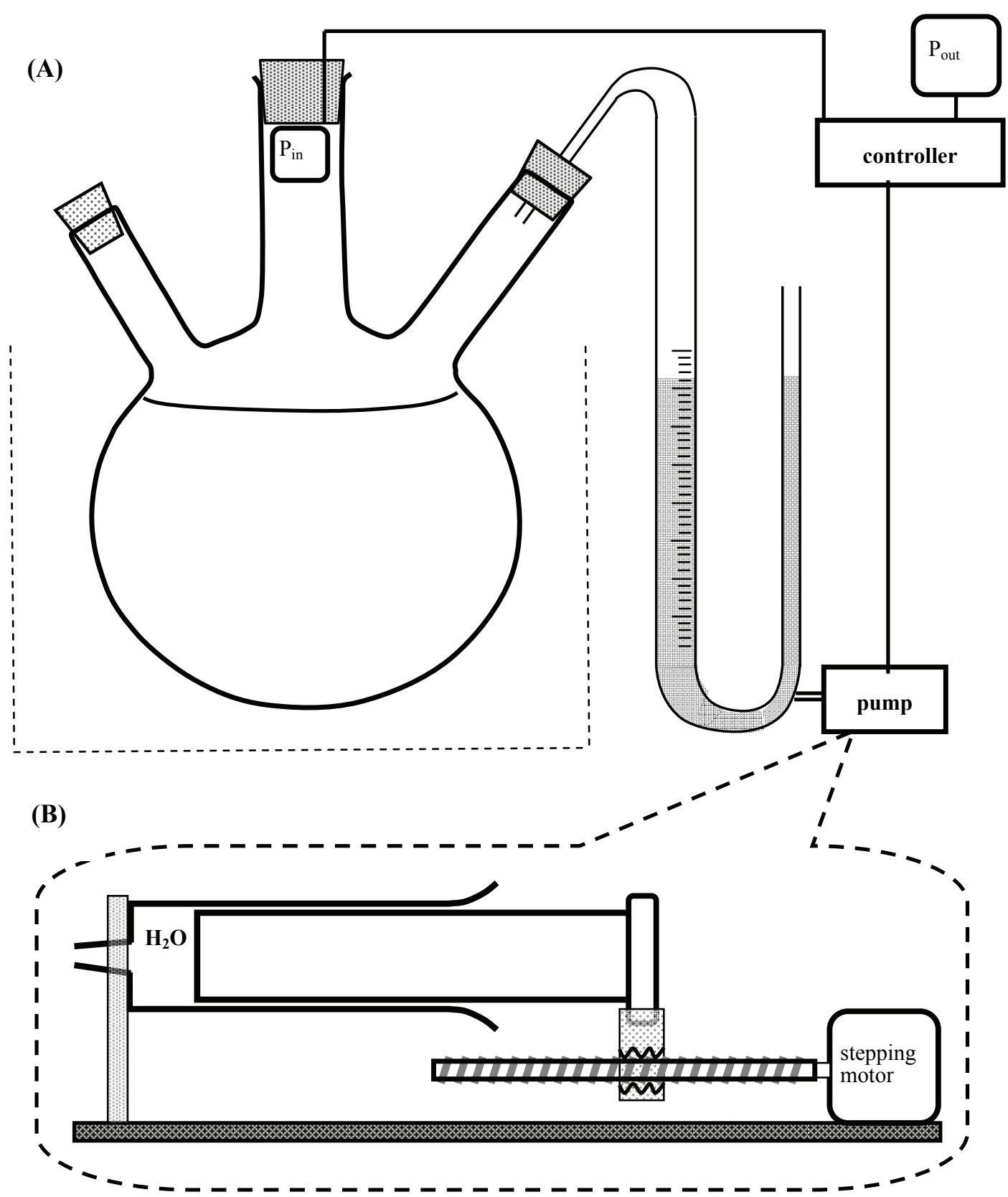

Fig. 1 Illustration of the volumetric cell structure $(\bar{A}) \overline{c o m p o s e d}$ of the flask, the manometer, the controller, the pump. (B) shows the detailed structure of the pump.

thermal expansion of air. The variation of gas volume with temperature was linear in the domain of $10{ }^{\circ} \mathrm{C}$ to $80{ }^{\circ} \mathrm{C}$, and was reproducible for the ascent and the descent of the temperature without hysteresis. Therefore, no leakage of air was observed.

Water was distilled and then ion-exchanged. All the chemicals were of analytical grade. Hydrogen gas used was of 0.05 vol ppm grade, commercially available in a cylinder bottle.

The pressure in the flask was monitored with an absolute pressure sensor, MPL115A2 (Freescale Semiconductor, Austin) with $0.04 \mathrm{kPa}$ nominal accuracy in the range less than $115.0 \mathrm{kPa}$. Two sensors were equipped, one being at the top of the mouth of the flask for monitoring the pressure within the flask, the other being for the atmospheric pressure. 
The controller, Arduino Ethernet R3, recorded $P_{\text {in }}$ and $P_{\text {out }}$ at a given time, and adjusted water volume with the stepping motor so that $P_{\text {in }}=P_{\text {out. }}$. It was driven with the homemade software.

The experimental procedures were

(1) To prepare $1 \mathrm{dm}^{-3}$ aqueous solution of $0.3 \mathrm{mM}$ $\left(\mathrm{M}=\mathrm{mol} \cdot \mathrm{dm}^{-3}\right) \mathrm{KMnO}_{4}+30 \mathrm{mM} \mathrm{H}_{2} \mathrm{SO}_{4}$ in the round flask into which a magnetic stirrer was put;

(2) To set out the volumetric apparatus without water in the manometer;

(3) To keep temperature of the flask in a thermo-controlled bath;

(4) To bubble hydrogen gas for 30 min into the solution in the thermo-controlled flask;

(5) To apply ultrasonication to the flask in order to remove visible hydrogen gas bubbles attached on the inner wall of the flask;

(6) To blow nitrogen gas on the surface of the solution for $20 \mathrm{~s}$ through another neck to the water-unfilled manometer in order to replace $\mathrm{H}_{2}$ by $\mathrm{N}_{2}$ in the gas phase of the flask;

(7) To fill water in the manometer;

(8) To insert an acid-rinsed platinum wire $0.5 \mathrm{~mm}$ in diameter and $250 \mathrm{~cm}$ long into the flask as the oxidation catalyst of $\mathrm{H}_{2}$ gas;

(9) To seal the flask, and to set in ca. $25{ }^{\circ} \mathrm{C}$ water bath;

(10) To drive the pressure-injector apparatus; and

(11) To record injected and withdrawn volumes of water and two pressure values every 30 seconds.

Platinum powder might be used for the catalyst of the rapid oxidation. However, it causes some problems of inclusion of air bubbles and removal of reaction byproducts.

Voltammetry was made in $0.5 \mathrm{M} \mathrm{KCl}+0.01 \mathrm{M}$ $\mathrm{NaOH}$ solution at the platinum disk electrode $1.6 \mathrm{~mm}$ in diameter. The reference electrode was $\mathrm{Ag} / \mathrm{AgCl}(3$ $\mathrm{M} \mathrm{KCl}$ ), and the counter electrode was a Pt coil. The potentiostat was HECS-1112 (Fuso, Kawasaki). Voltammetric scan was started at a given period after bubbling hydrogen gas for $30 \mathrm{~min}$. Hydrogen gas was filled over the aqueous solution during the voltammetry.

Dynamic light scattering (DLS) was obtained with Zeta Sizer (Malvern Instruments, UK).

\section{Results and Discussion}

Fig. 2 shows the size-distributions of bubbles measured by DLS in the air-isolated vessel after several periods of $\mathrm{H}_{2}$ bubbling. Dispersed bubbles became smaller as the bubbled solution was left out longer. This is because some bigger bubbles float up to disappear and some are dispersed into smaller bubbles. When bubbled solution was ultrasonicated for a half minute, DLS signals disappeared soon. They recovered after a few minutes when the solution was left without ultrasonication. Therefore, ultrasonication should disperse bubbles with unspecified size or uniformly distributed size.

We predict that the volume of the $\mathrm{H}_{2}$ gas decreases with the time by the oxidation of the gas and reaches a steady state value which is equivalent to the amount of gaseous state in saturated $\mathrm{H}_{2}$ solution. This prediction is guaranteed under the following conditions, in which (a)-(d) and (e)-(h) are conditions before and the after the oxidation, respectively:

(a) $\mathrm{H}_{2}$ bubbles large enough to be irrelevant to the saturation should float up completely before the flask is sealed against the atmosphere.

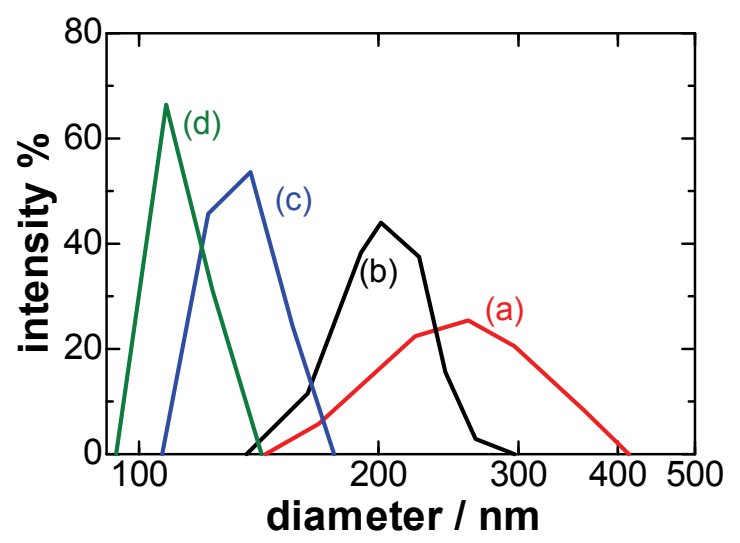

Fig. 2 Size distribution of $\mathrm{H}_{2}$ bubbles measured by the DLS (a) 1, (b) 20, (c) 40 and (d) 60 min after $\mathrm{H}_{2}$ bubbling. Their average diameters of bubbles at the peak are (a) 0.25 , (b) 0.20 , (c) 0.15 and (d) $0.11 \mu \mathrm{m}$, respectively. 
(b) There should be no bubble attached on inner wall of the flask.

(c) There should no $\mathrm{H}_{2}$ gas over the surface of the solution.

(d) The starting time of the volumetry should be the initiation of the oxidation by adding the Pt catalyst.

(e) The equation of the state of an ideal gas should be valid under the present conditions.

(f) The gas should not leak from the apparatus.

(g) There is neither variation of temperature or that of the atmospheric pressure during volumetry.

(h) The inner pressure should be kept to be the atmospheric pressure.

We confirmed in condition (b) that bubbles adsorbed on the inner surface of the flask disappeared by ultrasonication. Problem (c) was solved by purging $\mathrm{H}_{2}$ with $\mathrm{N}_{2}$ into the gas phase for $10 \mathrm{~s}$ immediately after stopping the $\mathrm{H}_{2}$ bubbling. Condition (a) was satisfied with the working periods of both the ultrasonication and the purge of $\mathrm{H}_{2}$ by $\mathrm{N}_{2}$. Problem (d) is the determination of the initial time. Under conditions (a)-(d), we started measuring the pressures and temperature each $30 \mathrm{~s}$.

The equation for the state of a non-ideal gas (e) can be represented by the Van der Waals equation, $(p+$ $\left.a V_{\mathrm{m}}^{-2}\right)\left(V_{\mathrm{m}}-b\right)=R T$ for constants $a=0.2452 \mathrm{dm}^{6}$ atm $\cdot \mathrm{mol}^{-2}, b=0.0265 \mathrm{dm}^{3} \cdot \mathrm{mol}^{-1}$ [41] and the molar volume $V_{\mathrm{m}}=24.46 \mathrm{dm}^{3}$ at $25{ }^{\circ} \mathrm{C}$. The deviation of the value of $\left(p+a V_{\mathrm{m}}^{-2}\right)\left(V_{\mathrm{m}}-b\right)$ from that of the ideal gas is $0.07 \%$ for our conditions. As a result, hydrogen gas can be regarded as an ideal gas. The leakage of gas (f) was examined in the air-saturated aqueous solution for one day's measurement during which the atmospheric pressure varied by $3 \mathrm{hPa}$. The inner pressure followed the atmosphere pressure within $\pm 0.14 \mathrm{hPa}$ errors.

It was difficult for us to control accurately the temperature and the atmospheric pressure, because the atmospheric pressure always changed over a day due to weather. We tried to correct the volume of added water from the equation for an ideal gas when the temperature and the atmospheric pressure vary with measurement time. We consider variation of the gas volume $V_{0}$ of the flask plus the $U$-shaped tube when the environment pressure and the temperature vary from slightly from $p_{0}$ and $T_{0}$. If the temperature increases by $\Delta T$ at the constant pressure, the volume change is given by $\Delta V=\left(\Delta T / T_{0}\right) V_{0}$ from the equation for an ideal gas. When the pressure increases by $\Delta p$ at a given temperature, the volume change is given by $\Delta V=-\left(\Delta p / p_{0}\right) V_{0}$. If both the temperature and the pressure change simultaneously by small amounts, the volume change to be corrected can be a sum of the two changes:

$$
V_{\text {crct }}=\left(\Delta T / T_{0}-\Delta p / p_{0}\right) V_{0}
$$

This amount should be added to the measured volume change. The numerical volume of the gas phase in the flask was determined by subtraction of the aqueous solution $\left(1 \mathrm{dm}^{3}\right)$ from the volume of the whole flask filled with water $\left(1.320 \mathrm{dm}^{3}\right)$. The volumes of the $U$-shaped manometer and the other connecting glass tubes were estimated from the geometry to be $0.22 \mathrm{dm}^{3}$ and $0.03 \mathrm{dm}^{3}$, respectively. The total gas volume to be corrected, $V_{0}$, was 0.57 $\mathrm{dm}^{3}$. The measured change in the gas volume, $V_{\mathrm{m}}$, was corrected to $V_{\mathrm{m}}+V_{\text {cret }}\left(\equiv V_{\mathrm{m}, \mathrm{c}}\right)$. Values of $V_{\mathrm{m}}$ are the same as the volume of added water which compensated a decrease in gas volume. Fig. 3 shows time-variations of $V_{\mathrm{m}}$ and $V_{\mathrm{m}, \mathrm{c}}$. The periodical variation with one day's cycle means that temperature variation is larger than the pressure.

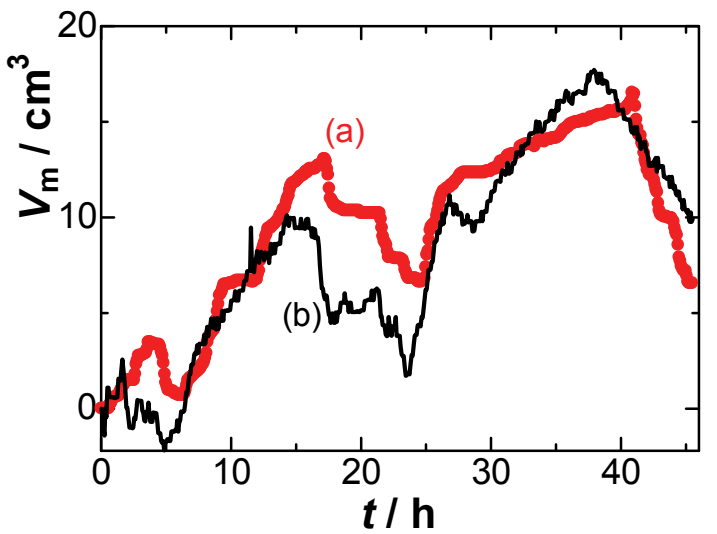

Fig. 3 Time variations of (a) the volume of dispersed air, $V_{\mathrm{m}}$, and (b) the corrected volume, $V_{\mathrm{m}, \mathrm{c}}$, when the flask was filled with $1 \mathrm{dm}^{3}$ water including air. 
Fig. 4 shows time-variations of $V_{\mathrm{m}, \mathrm{c}}$ (corrected volume of added water) at two temperatures at $\mathrm{H}_{2}$ bubbling. The increase in the volumes means the gradual consumption of dispersed $\mathrm{H}_{2}$ bubbles by the oxidation. The consumption rate decreased with the time and then the volume reached the limiting value, $V_{\text {lim, }}$ which should be the volume of $\mathrm{H}_{2}$ in the bubble form. The Pt wire after long use was coated with black slug, which blocked the oxidation rate. Therefore the oxidation rates in Fig. 4 are not suitable for quantitative analysis. The $\mathrm{Pt}$ wire was treated with concentrated nitric acid to dissolve the slug for the further experimental runs.

Values of $V_{\text {lim }}$ obtained at several temperatures at bubbling are listed in Table 1 , in which $V_{\lim }$ is transformed into the molar numbers of $\mathrm{H}_{2}$ through the state equation for an ideal gas at $25^{\circ} \mathrm{C}$. The times of reaching $V_{\lim }$ were almost common except for $60{ }^{\circ} \mathrm{C}$.

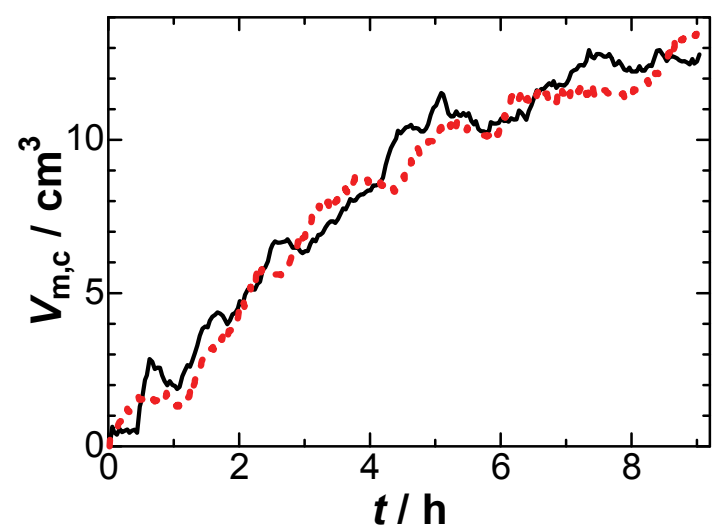

Fig. 4 Time-variations of the $\mathrm{H}_{2}$ corrected gas-volume, $V_{\mathrm{m}, \mathrm{c}}$, at temperature (line) $10^{\circ} \mathrm{C}$ and (dotted line) $40^{\circ} \mathrm{C}$ at $\mathrm{H}_{2}$ bubbling after $\mathrm{Pt}$ catalyst was inserted to the flask filled with $1 \mathrm{dm}^{3} \mathrm{H}_{2}$-saturated aqueous solution of $0.3 \mathrm{mM}$ $\mathrm{KMnO}_{4}+30 \mathrm{mM} \mathrm{H}_{2} \mathrm{SO}_{4}$.

Table 1 Values of $V_{\lim }$ and moles of dispersed $\mathrm{H}_{2}$ gas at temperatures during bubbling.

\begin{tabular}{llll}
\hline $\begin{array}{l}T /{ }^{\circ} \mathrm{C} \text { at } \\
\text { bubbling }\end{array}$ & Time at $V_{\mathrm{lim}} / \mathrm{h}$ & $V_{\mathrm{lim}} / \mathrm{cm}^{3}$ & Gaseous $\mathrm{H}_{2}$ gas $/ \mathrm{mmol}$ \\
\hline 5 & 5.5 & 12 & 0.52 \\
10 & 5.0 & 11 & 0.48 \\
15 & 5.5 & 8 & 0.35 \\
20 & 6.0 & 9 & 0.39 \\
25 & 6.0 & 11 & 0.48 \\
40 & 6.0 & 12 & 0.52 \\
60 & 4.0 & 4 & 0.17 \\
\hline
\end{tabular}

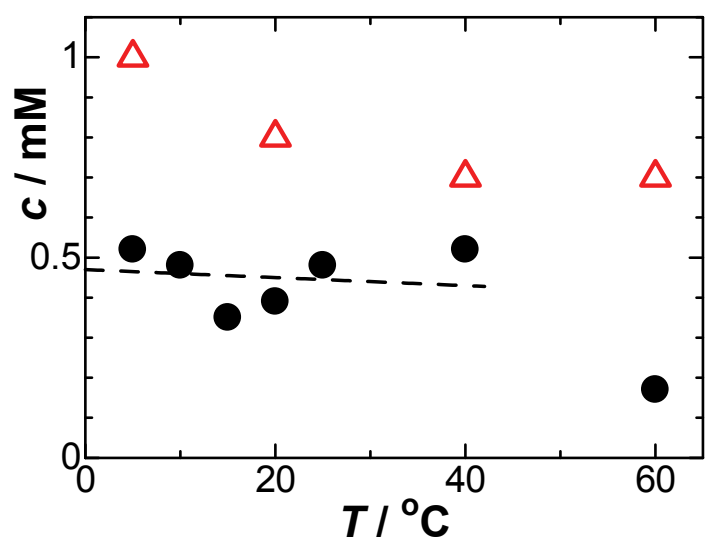

Fig. 5 Temperature dependence of concentrations of gaseous $\mathrm{H}_{2}$ (circles) and saturated $\mathrm{H}_{2}$ concentrations (triangles).

The shorter time at $60{ }^{\circ} \mathrm{C}$ yielded smaller value of $V_{\text {lim }}$, suggesting a loss of $\mathrm{H}_{2}$ gas by rapid aggregation of micro-bubbles before starting the volumetry. Fig. 5 shows the concentrations of gaseous $\mathrm{H}_{2}$ calculated from $V_{\lim }$ with the temperature of $\mathrm{H}_{2}$ bubbling, together with the reported values of $\mathrm{H}_{2}$-saturated concentrations [42]. The gaseous concentrations do not vary with the temperature within our errors. A half amount of $\mathrm{H}_{2}$ in the $\mathrm{H}_{2}$-saturated solution takes bubbles rather than the hydrated form.

A question is which concentration of the hydrated $\mathrm{H}_{2}$ or saturated total $\mathrm{H}_{2}$ can participate in the oxidation of $\mathrm{H}_{2}$ in the dispersed solution by voltammetry or $\mathrm{H}_{2}$-fuel cells. We made voltammetry both at a small electrode and a normal-sized electrode in order to evaluate simultaneously the concentration and the diffusion coefficient of $\mathrm{H}_{2}[10,43]$. Since the concentration by the voltammetry was close to the reported value of the saturated concentration, both the concentrations can take part in the oxidation. According to the concept of charge transfer steps, only solvated molecules can react at electrodes rather than gaseous molecules, because of solvation and charge neutralization. The gaseous $\mathrm{H}_{2}$ should be dissolved rapidly on the voltammetric time scale to actually keep the concentration of hydrated $\mathrm{H}_{2}$, as if hydrated concentration was to be the saturated one. That is, the bubble form works as a source of super-saturation. 


\section{Conclusions}

Hydrogen-saturated aqueous solution with the concentration of ca. $0.8 \mathrm{mM}$ contains hydrated hydrogen and bubbled hydrogen with a similar concentration, $0.4 \mathrm{mM}$, according to volumetry of the solution when bubbles are oxidized to hydrated hydrogen. Although the thermodynamically saturated hydrogen gas should be in the hydrated form, actually saturated hydrogen solution includes the $\mathrm{H}_{2}$-bubbled form by a half in molar numbers of $\mathrm{H}_{2}$. In other words, the $\mathrm{H}_{2}$-saturated solution is supersaturated. The bubbled $\mathrm{H}_{2}$ is rapidly transformed into the hydrated form on the voltammetric time scale. Therefore all the amount of $\mathrm{H}_{2}$ in the saturated solution can be used for the oxidation as if it were present in the hydrated form.

It is generally difficult to chemically distinguish dispersed bubbles from the hydrated molecules. Volumetry is a technique of determining quantitatively amount of gas volume, discriminating against the hydrated form. However, some errors are incorporated in the measured volume, including removal of large bubbles in solution as well as on a vessel, removal of $\mathrm{H}_{2}$ in the dead space in the vessel, a consumption method of the gas at slow rate, correction against variations of atmospheric temperature and pressure, and prevention of gas leakage.

\section{Acknowledgments}

The authors wish to express their appreciation to Mr. Hirokazu Toda and Dr. Nishiumi Toyohiko for developing the volumetric instrument and the homemade software.

\section{References}

[1] Atkins, P. W. 1998. Physical Chemistry. Sixth edition, Oxford: Oxford University Press, 173.

[2] Battino, R., and Clever, H. L. 1966. "The Solubility of Gases in Liquids." Chem. Rev. 66: 395-463.

[3] Benson, B. B., and Krause, D. 1976. "Empirical Laws for Dilute Aqueous Solutions of Nonpolar Gases." J. Chem.
Phys. 64: 689-709.

[4] Rettich, T. R., Handa, Y. P., Battino, R., and Wilhelm, E. 1981. "Solubility of Gases in Liquids. 13. High-Precision Determination of Henry's Constants for Methane and Ethane in Liquid Water at 275 to 328 K." J. Phys. Chem. 85: 3230-7.

[5] Young, C. L., Ed. 1981. "IUPAC Solubility Data Series." Vol. 5/6, In Hydrogen and Deuterium. Oxford, England: Pergamon Press.

[6] Sander, R. 2014. “Compilation of Henry's Law Constants." version 3.99, Atmos. Chem. Phys. Discuss. (14): 29615-30521.

[7] Kumelan, J., Kamps, A. P.-S., Tuma, D., and Maurer, G. 2007. "Solubility of the Single Gases $\mathrm{H}_{2}$ and $\mathrm{CO}$ in the Ionic Liquid [bmim] $\left[\mathrm{CH}_{3} \mathrm{SO}_{4}\right]$." Fluid Phase Equil. (260): 3-8.

[8] Horstmann, S., Grybat, A., and Kato, R. 2004. "Experimental Determination and Prediction of Gas Solubility Data for Oxygen in Acetonitrile." J. Chem. Thermodyn. (36): 1015-8.

[9] Raposo, R. R., Calvino, E., and Esteso, M. A. 2008. “A New Electrochemical Method for the Determination of Gas Solubility in Aqueous Solutions." J. Electroanal. Chem. 617: 157-63.

[10] Aoki, K., Toda, H., Yamamoto, J., Chen, J., and Nishiumi, T. 2012. "Is Hydrogen Gas in Water Present as Bubbles or Hydrated Form.” J. Electroanal. Chem. 668: 83-9.

[11] Nishiki, Y., Aoki, K., Tokuda, K., and Matsuda, H. 1986. "Effect of Gas Evolution on Current Distribution and Ohmic Resistance in a Vertical Cell under Forced Convection Conditions." J. Appl. Electrochem. 16: 615-25.

[12] Vilar, E. O., Cavalcanti, E. B., and Albuquerque, I. L. 2011. "A Mass Transfer Study with Electrolytic Gas Production." Adv. Topics Mass Trans. 9: 175-90.

[13] Vogt, H. 1993. "The Role of Single-Phase Free Convection in Mass Transfer at Gas Evolving Electrodes-I. Theoretical." Electrochim. Acta 38: 1421-6.

[14] Vogt, H. 1993. "The Role of Single-Phase Free Convection in Mass Transfer at Gas Evolving Electrodes-II. Experimental Verification." Electrochim. Acta. 38: 1427-31.

[15] Janssen, L., and Barendrecht, E. 1979. "The Effect of Electrolytic Gas Evolution on Mass Transfer at Electrodes." Electrochim. Acta. 24: 693-9.

[16] Whitney, G. M., and Tobias, C. W. 1988. "Mass-Transfer Effects of Bubble Streams Rising near Vertical Electrodes." AIChE J. 34: 1981-95.

[17] Tawfik, M. E., and Diez, F. J. 2014. "On the Relation between Onset of Bubble Nucleation and Gas Supersaturation Concentration." Electrochim. Acta. 146: $792-7$. 
[18] Dale, S. E. C., Vuorema, A., Sillanpää, M., Weber, J., Wain, A. J., Barnes, E. O., Compton, R. G., and Marken, F. 2014. Electrochim. Acta. 125: 94-100.

[19] Li, C., Aoki, K. J., Nishiumi, T., and Chen, J. 2013. "Salt-Free Electrolysis of Water Facilitated by Hydrogen Gas in Thin Layer Cell." Report Electrochem. 3: 7-15.

[20] Levich, V. G. 1962. Physicochemical Hydrodynamics. Englewood Cliffs. N. J. New Jersey: Prentice-Hall.

[21] Matsushima, H., Iida, T., and Fukunaka, Y. 2013. "Gas Bubble Evolution on Transparent Electrode during Water Electrolysis in a Magnetic Field.” Electrochim. Acta. 100: 261-4.

[22] Matsushima, H., Fukunaka, Y., and Kuribayashi, K. 2006. "Water Electrolysis under Microgravity: Part II. Description of Gas Bubble Evolution Phenomena." Electrochim. Acta. 51: 4190-8.

[23] Kulikovsky, A. A. 2006. "Bubbles in the Anode Channel and Performance of a DMFC: Asymptotic Solutions." Electrochim. Acta. 51: 2003-11.

[24] Moudgil, B. M., Somasundaran, P., and Lin, I. 1974. "Automated Constant Pressure Reactor for Measuring Solubilities of Gases in Aqueous Solutions." J. Rev. Sci. Instrum. 45: 406-9.

[25] Tominaga, T., Battino, R., Gorowara, H. K., Dixon, R. D., and Wilhelm, E. 1986. "Solubility of Gases in Liquids. XVII: The Solubility of $\mathrm{He}, \mathrm{Ne}, \mathrm{Ar}, \mathrm{Kr}, \mathrm{H}_{2}, \mathrm{~N}_{2}, \mathrm{O}_{2}, \mathrm{CO}$, $\mathrm{CH}_{4}$, and $\mathrm{SF}_{6}$ in Tetrachloromethane at 283-318 K." $J$. Chem. Eng. Data 31: 175-80.

[26] Kato, M., Aizawa, K., Kanahira, T., and Ozawa, T. 1991. "A New Experimental Method of Vapor-Liquid Equilibria at High Pressures." J. Chem. Eng. Jpn. 24: 767-71.

[27] Serra, M. C. C., and Palavra, A. M. F. 2003. "Solubility of 1-Butene in Water and in a Medium for Cultivation of a Bacterial Strain.” J. Solution Chem. 32: 527-34.

[28] Dias, A. M. A., Bonifacio, R. P., Marrucho, I. M., Padua, A. A. H., and Costa-Gomes, M. F. 2003. "Solubility of Oxygen in N-Hexane and in N-Perfluorohexane. Experimental Determination and Prediction by Molecular Simulation." Phys. Chem. Chem. Phys. 5: 543-9.

[29] Podesta, J. J., Estrella, C. N., and Esteso, M. A. 1996. "Evaluation of the Absorption on Mild Steel of Hydrogen Evolved in Glucose Fermentation by Pure Cultures of Clostridium Acetobutylicum and Enterobacter." Sensor Actuator. B 32: 27-31.

[30] Bouchet, R., Siebert, E., and Vitter, G. 2000. "Polybenzimidazole-Based Hydrogen Sensors I. Mechanism of Response with an E-TEK Gas Diffusion Electrode." J. Electrochem. Soc. 147: 3125-30.
[31] Fischer, K., and Wilken, M. 2001. "Experimental Determination of Oxygen and Nitrogen Solubility in Organic Solvents up to $10 \mathrm{MPa}$ at Temperatures between 298 K and 398 K.” J. Chem. Thermodyn. 33: 1285-308.

[32] Kumelan, J. A., Kamps, P. -S. O., Urukova, I., Tuma, D., and Maurer, G. 2005. "Solubility of Oxygen in the Ionic Liquid [bmim] $\left[\mathrm{PF}_{6}\right]$ : Experimental and Molecular Simulation Results.“ J. Chem. Thermodyn. 37: 595-620.

[33] Rettich, T. R., Brttino, R., and Wilhelm, E. 2000. "Solubility of Gases in Liquids. 22. High-Precision Determination of Henry's Law Constants of Oxygen in Liquid Water from $\mathrm{T}=274 \mathrm{~K}$ to $\mathrm{T}=328 \mathrm{~K}$." J. Chem. Thermodyn. 32: 1145-56.

[34] Aoki, K., Li, M., Chen, J., and Nishiumi, T. 2009. "Spontaneous Emulsification at Oil-Water Interface by Tetraalkylammonium Chloride." Electrochem. Commun. 11: 239-41.

[35] Li, M., Aoki, K., Chen, J., and Nishiumi, T. 2011. "Voltammetric Determination of Concentrations of Ferrocene-Included Nitrobenzene Droplets in Water." J. Electroanal. Chem. 655: 159-63.

[36] Shchipunov, Y. A., and Schmiedel, O. 1996. "Phase Behavior of Lecithin at the Oil/Water Interface." Langmuir 12: 6443-5.

[37] Pautot, S., Frisken, B. J., Cheng, J.-X., Xie, X. S., and Weitz, D. A. 2003. "Spontaneous Formation of Lipid Structures at Oil/Water/Lipid Interfaces." Langmuir 19: 10281-7.

[38] Gonza'lez-Ochoa, H., Ibarra-Bracamontes, L., and Arauz-Lara, J. L. 2003. "Two-Stage Coalescence in Double Emulsion.” Langmuir 19: 7837-40.

[39] Sacanna, S., Kegel, W. K., and Philipse, A. P. 2007. "Spontaneous Oil-in-Water Emulsification Induced by Charge-Stabilized Dispersions of Various Inorganic Colloids." Langmuir 23: 10486-92.

[40] Aoki, K. 2011. "Size-Distribution of Droplets in Emulsions by Statistical Mechanics Calculation." $J$. Colloid Interface Sci. 360: 256-61.

[41] Reid, R. C., Prausnitz, J. M., and Poling, B. E. 1987. The Properties of Gases and Liquids, Fourth Edition, New York: McGraw-Hill, 6-43.

[42] Young, C. L., Ed., 1981. IUPAC Solubility Data Series, Vol. 5/6, Hydrogen and Deuterium, Oxford, England: Pergamon Press.

[43] Zhang, H., Aoki, K., Chen, J., Nishiumi, T., Toda, H., and Torita, E. 2011. "Voltammetric Determination of Both Concentration and Diffusion Coefficient by Combinational Use of Regular and Microelectrodes." Electroanalysis 23: 947-52. 